\title{
Edítoríal.
}

\section{PHILOSOPHY AND MEDICINE.}

THOSE who are engaged with medical research or the practical problems of the clinic do not as a rule concern themselves to any extent with the development of philosophic thought. It is natural that this should be so. Philosophy is not concerned with the same problems as science or medicine : its scope is wider: While philosophy assimilates the facts of science, it does so only to understand life as a whole. It aims at formulating general principles which will serve to harmonize all phenomena and to bring them into a consistent and understandable scheme. "The aim of science is the description ofog facts, the aim of philosophy their interpretation." Thus the philosopher sets himself to solve more difficult problems than doeso the scientist, who concerns himself with the descriptive formulation of one specific category of facts; and in consequence, not only does he need to possess a wider range of knowledge, but he must have special qualities of mind to enable him to pursue his task. And there. is a certain remoteness about his work which creates an impression that his efforts are unproductive and devoid of contact with the practical problems we endeavour to solve. Philosophy is difficult to understand; its outlines are vague; there seems nothing to impinge against as it were. Yet it is not necessarily unpractical, and it sometimes happens that the philosopher, while striving to discover a unity in phenomena, and because of his wider vision, is able to furnish an interpretation of the facts discovered by the scientist which is considerably in advance of his time. Such a possibility is naturally most likely to be realized in the spheres of neurology and psychology, the problems of which, in their wider aspects, are especially the subject of consideration by the philosopher. Striking confirmation of such a view is to be found in an article by Dr. R. Mourgue, a French psychiatrist, published in a recent number of the Revue de métaphysique et de morale.* The article is concerned with the philosophic works of M. Bergson, and since it concerns matters of vital significance to

* "Le point de vue neuro-biologique dans l'œuvre de M. Bergson et les données actuelles de la science", Revue de métaphysique et de morale, 1920, jan.-mars. 
the development of neurology and psychopathology, a brief reference to its contents may here suitably be made.

Up to the end of the last century neurophysiology and psychology were dominated by the classical theory of 'centres' - a kind of 'scientific phrenology', as Professor Watson has said. The 'doctrine of faculties', 'psychological atomism', and 'associationism' were of course based on the assumption that independent psychic elements were localized in certain areas of the brain. Such theories being current at the time, it is easy to understand, as Dr. Mourgue points. out, that neurologists were but little prepared to comprehend the scientific interest of the views expressed in Matière et mémoire, published by Bergson in 1896. Yet these views anticipated to a remarkable degree the facts which scientific observations have elucidated during the last twenty years. In a comprehensive survey of the development of neurology during this period, Dr. Mourgue shows this to be the case. He indicates the basic principles upon which Bergson founded his philosophy, and he shows, by reference to the work of von Monakow, Sherrington, Graham Brown, Bechterew, Elliot Smith, von Uexkull, Head, and others, how these principles have been confirmed by the actual facts which science has been able to furnish.

We cannot here enter into the details included in this article; but the central contention it is designed to develop may be illustrated by a quotation from Bergson : "The truth is that my nervous system, interposed between the objects which stimulate my body and those which I could influence, plays the rôle of a simple conductor, which transmits, distributes, or inhibits some movement". If we now compare this, at the time, daring statement, with a quotation from our last editorial, it will be apparent to what an extent Bergson's views coincided with those which exist to-day. "We must not suppose that the psychic phenomenon of sensation is localized by the physiologist in the so-called sensory regions. All that is claimed is that these different regions or centres form relay stations for nerve impulses derived from particular classes of stimuli; that these nerve impulses are perhaps rearranged there; and that they are transmitted thence to some more common motor mechanism." The resemblance between the quotations is obvious, and it is certainly remarkable that the facts of scientific observation should prove to be so clearly in accord with the views expressed by the philosopher many years before.

Briefly it may be said that it is the stress which Bergson gives to movement which renders his views of such vital significance to the psychologist. In this respect, as Dr. Mourgue shows, he approached his problems from an essentially biological point of view-the term biological here meaning that method which aims at explaining physiological or pathological phenomena in living beings provided with a 
nervous system, in a language as objective as possible and applicable in consequence to the whole animal series. To interpret psychological phenomena in terms of bodily movement is a truly objective method, and, as the following quotations show, it is in terms of movement that Bergson defines perception. "The nervous system is in no sense an apparatus which may serve to fabricate, or even to prepare, representations. Its function is to receive stimulations, to provide motor apparatus, and to present the largest number of these apparatuses to a given stimulus. . . . This conductor is composed of an enormous number of threads which stretch from the periphery to the centre, and from the centre to the periphery. As many threads as pass from the periphery to the centre, so many points of space are there able to make an appeal to my will and to put, as it were, an elementary question to my motor activity. Every such question is what is termed perception. ... Every perception is prolonged into nascent action. . . Perception measures our possible actions on things, and thereby, inversely, the possible actions of things on us. . . . The actuality of a perception lies in its activity, in the movements which prolong it, and not in its greater intensity. . . . The concrete feeling that we have of presento reality consists of the consciousness of the actual movements whereby our organism is responding naturally to stimuli."

In such phrases Bergson makes it clear that the psyche must be interpreted and understood in terms of action and behaviour. Suchb a view harmonizes with the whole trend of modern psychology, which is now chiefly concerned with the reactions which the individual makeso in response to stimuli or situations. The focus of interest has now shifted from th? introspective study of consciousness to the more objective study of behaviour - of man in action. And by action is not only meant voluntary movements and speech, but also implicit action - the nascent movements on which Bergson lays such stresssuch as bodily postures, attitudes, gestures, tensions, and autonomic disturbances. This tendency to interpret the psychophysical organism in terms of movement or conduct finds its extreme expression in behaviourism, a school of psychology which indicates the extent of the reaction against the introspective and academic psychology of the past. Criticism of the behaviourist position might be made on various grounds, notably from the fact that it would seem to ignore the omnipresent fact of self-consciousness; but in so far as it carries the interpretation of the individual in terms of movement to its logical conclusion, so that thought itself becomes implicit bodily activity, it undoubtedly lays the foundation for the erection of a scientific, objective, and practical psychology - a psychology which may be relied upon to furnish contributions of definite value for the future reconstruction of our social organization. 
It is not only the notion of movement upon which Bergson lays so much stress, but also that of development. Throughout his philosophic works he emphasizes the evolutionary point of view, and he makes it clear that man is a historical being whose reactions are only explicable in terms of his individual and racial past. "The past,". he writes, "is preserved by itself, automatically. In its - entirety, probably, it follows us at every instant ; all that we have felt, thought, and willed from our earliest infancy is there, leaning over the present which is about to join it, pressing against the portals of consciousness that would fain leave it outside. . . . What are we, in fact, what is our character, if not the condensation of the history we have lived from our birth-nay, even before our birth, since we bring with us prenatal dispositions? Doubtless we think with only a small part of our past, but it is with our entire past, including the original bent of our soul, that we desire, will, and act." Such views are, of course, strikingly in accord with the facts that modern psychology has recently brought to light. The aim of psycho-analysis is to unravel the historical past, and the evidence which Freud has brought forward in proof of the view that our present reactions are strictly determined by the influences of the past, perhaps constitutes his greatest contribution to psychology. "From whatever angle we come to the study of the individual-whether on account of a strike, a murder, or a stomachache-that study inevitably leads us to a review of the past experiences of the individual, for we are what the past has made us. We react to the present in a manner largely determined by our past experience. The past is not dead or buried; it is part of the living fabric of our present character." Thus writes a modern psychopathologist in phrases which remind us curiously of those which we have quoted from Bergson, and of which we are now only beginning to realize the full significance.

It would be easy to expand this subject, and to indicate other directions in which Bergson has been able to illuminate the problems we endeavour to solve. In the present instance, however, it suffices to bring into prominence the significance of the two great biological principles-movement and development-upon which Bergson might be said to have erected his philosophy, because we feel, with Dr. Mourgue, that these same principles might well become the foundation for a truly scientific understanding of human behaviour. 